\title{
Adsorption of Phosphate Ions on Novel Mg/Fe/Al Hydroxides (MFA) Prepared at Different $\mathrm{Mg}^{2+} / \mathrm{Fe}^{3+} / \mathrm{Al}^{3+}$ Ratios
}

\author{
Takehiro Nakamura, Riku Nagafuji, Fumihiko Ogata, and Naohito Kawasaki* \\ Faculty of Pharmacy, Kindai University; 3-4-1 Kowakae, Higashi-Osaka, Osaka 577-8502, Japan. \\ Received July 31, 2019; accepted December 24, 2019
}

In this study, we prepared novel Mg/Fe/Al hydroxides (MFA series: denoted by MFA1, MFA2, MF, and MA) and investigated their properties using scanning electron microscopy, $X$-ray diffraction, the specific surface area, and amount of hydroxyl groups. Additionally, the phosphate adsorption capabilities of the MFA series or Fe-Mg type hydrotalcites (FHT3.0 and FHT5.0) were evaluated by examining the effects of the solution $\mathrm{pH}$ and contact time, and analyzing the adsorption isotherm and desorption characteristics. In MFA1, a strong correlation exists between the amount of adsorbed phosphate ions and surface hydroxyl groups, with a correlation coefficient of 0.95 . The adsorption kinetics data fitted using the pseudo-second-order model performs better than the pseudo-first-order model. The adsorption isotherm data were also fitted using both the Freundlich and Langmuir models. Finally, the phosphate ions adsorbed on the MFA1 surfaces were desorbed using sodium hydroxide solution. These results indicate that MFA1 offers great potential for phosphate ion adsorption from aqueous solutions and functions as a renewable adsorbent.

Key words $\mathrm{Mg}-\mathrm{Fe}-\mathrm{Al}$ type hydrotalcite; phosphate ion; adsorption; synthesis

\section{Introduction}

Phosphorus has been recognized as an essential macronutrient in aquatic environments. ${ }^{1,2)}$ However, excess phosphorus concentrations can cause eutrophication in the lakes and rivers. ${ }^{3,4)}$ Thus, discharge limits have been set to ensure effluent phosphate concentrations in wastewater to prevent eutrophication. Various methods are currently used to remove phosphate ions from wastewater such as active sludge, ion exchange, or precipitation using chemical methods, which incur high costs. Thus, the adsorption method was used in this study to remove the phosphate ions from wastewater, with the simple operation/process requiring low costs. Various previous studies have investigated the adsorption method using HUD/Al-HUD zeolite, ${ }^{5)}$ Fe-Bentnite, $\left.{ }^{6}\right) \mathrm{Zn}-\mathrm{Al}$ layered double hydroxide, ${ }^{7)} \mathrm{Al}$ hydroxide gel, ${ }^{8)} \mathrm{Mg} / \mathrm{Fe}$ double hydroxide, ${ }^{9)} \mathrm{Fe}$-doped activated carbon, ${ }^{10)}$ Calcined Ni hydroxide, ${ }^{11)}$ and Co hydroxide. ${ }^{12)}$ These studies have reported that a change in the combination of metals changes the characteristics of the composite adsorbents. In this study, we attempted to optimize the combination of metals in hydrotalcite-like compounds for the removal of phosphate ions.

Additionally, there are very few reports on three-metal composite adsorbents like $\mathrm{Mg}-\mathrm{Fe}-\mathrm{Al}$ hydroxides because their synthesis becomes difficult with increase in the number and type of metals. We thus investigated a simpler technique to synthesize these novel adsorbents.

In this study, we prepared novel $\mathrm{Mg} / \mathrm{Fe} / \mathrm{Al}$ hydroxides (MFA) at various ratios and investigated their phosphate adsorption behavior. The properties of the adsorbents, adsorption isotherms and kinetics, effect of the $\mathrm{pH}$ and temperature, and desorption ability were examined/evaluated. In conclusion, we found simple way of synthesize $\mathrm{Mg} / \mathrm{Fe} / \mathrm{Al}$ hydroxides, and the adsorbent have high capacity of phosphate ion adsorption, and can be repeatedly used. The results indicate that the novel adsorbents synthesized using simple processes are very useful for the removal of phosphate ions from wastewater.

\section{Experimental}

Materials $\mathrm{MgCl}_{2} \cdot 6 \mathrm{H}_{2} \mathrm{O}, \mathrm{FeCl}_{3} \cdot 6 \mathrm{H}_{2} \mathrm{O}, \mathrm{AlCl}_{3} \cdot 6 \mathrm{H}_{2} \mathrm{O}, \mathrm{Na}_{2} \mathrm{CO}_{3}$, and potassium dihydrogenphosphate were purchased from FUJIFILM Wako Pure Chemical Corporation (Japan). The $\mathrm{Fe}-\mathrm{Mg}$ type hydrotalcite (FHT) was obtained from Tomita Pharmaceutical Corporation, Ltd. (Japan), with FHT3.0: $\mathrm{Mg}^{2+}$ / $\mathrm{Fe}^{3+}=3.0$, and FHT5.0: $\mathrm{Mg}^{2+} / \mathrm{Fe}^{3+}=5.0$.

Adsorbent characteristics were evaluated using the following methods. Scanning electron microscopy (SEM) was performed with a JSM-5500LV instrument (JEOL, Japan). X-ray diffraction (XRD) analysis was performed using a Mini Flex II (Rigaku, Japan). The specific surface area of the adsorbent was measured using a NOVA4200e specific surface analyzer (Yuasa Ionic, Japan), while the amount of hydroxyl groups was measured using the fluoride ion adsorption method. ${ }^{13)}$ The phosphorus distribution on the MFA1 was measured using an electron micro-analyzer (EPMA, JXA-8530F, JEOL, Japan) at a beam diameter and accelerating voltage of $5 \mu \mathrm{m}$ and $15.0 \mathrm{kV}$, respectively. Electron spectroscopy for chemical analysis was carried out using an X-ray photoelectron spectroscopy system (AXIS-NOVA, Shimadzu Corp., Ltd., Japan).

MFA Preparation $\mathrm{Mg} / \mathrm{Fe} / \mathrm{Al}$ hydroxides at different metal ratios were synthesized based on the methods used for the synthesis of the $\mathrm{Mg}-\mathrm{Fe}-\mathrm{Al}$ hydrotalcite-like compounds in the study by Wimonsong et al., ${ }^{14)}$ with a few modifications. $\mathrm{MgCl}_{2} \cdot 6 \mathrm{H}_{2} \mathrm{O}, \mathrm{FeCl}_{3} \cdot 6 \mathrm{H}_{2} \mathrm{O}$, and $\mathrm{AlCl}_{3} \cdot 6 \mathrm{H}_{2} \mathrm{O}$ were used to prepare the $\mathrm{Mg} / \mathrm{Fe} / \mathrm{Al}$ hydroxides using four $\mathrm{Mg}$ : $\mathrm{Fe}: \mathrm{Al}$ molar ratios of $2.5: 0.5: 1$ (MFA1), 2.5:1:0.5 (MFA2), 2.5:1.5:0 (MF), and 2.5:0:1.5 (MA). $\mathrm{MgCl}_{2} \cdot 6 \mathrm{H}_{2} \mathrm{O}, \mathrm{FeCl}_{3} \cdot 6 \mathrm{H}_{2} \mathrm{O}$, or $\mathrm{AlCl}_{3} \cdot 6 \mathrm{H}_{2} \mathrm{O}$ were dissolved in water in a second flask, and the $\mathrm{pH}$ of the solution was adjusted to $9.0 . \mathrm{FeCl}_{3}$ was then added and mixed with the $\mathrm{MgCl}_{2}$ solution. Subsequently, $\mathrm{AlCl}_{3}$ solution and $4.0 \mathrm{~g}$ of $\mathrm{Na}_{2} \mathrm{CO}_{3}$ were added to the $\mathrm{Fe}-\mathrm{Mg}$ mixture and mixed vigorously. The precipitate was aged under reflux for $18 \mathrm{~h}$ at $90^{\circ} \mathrm{C}$, and then filtered, washed thoroughly with deionized water, and dried overnight at $50^{\circ} \mathrm{C}$. 
Amount of Phosphate Ions Adsorbed The adsorbent was added to the phosphate ion solution. The suspension was shaken at $100 \mathrm{rpm}$ for $24 \mathrm{~h}$ at $25^{\circ} \mathrm{C}$. The sample was then filtered through a $0.45 \mu \mathrm{m}$ membrane filter, and the filtrate concentration was measured using the iCAP-7600 analyzer (ICP-OES, Thermo Fisher Scientific Inc., Japan). The amount of adsorbed phosphate ions was calculated using Eq. (1) as shown below:

$$
q=\frac{\left(C_{0}-C_{\mathrm{e}}\right) V}{W}
$$

Where, $q$ is the amount of adsorbed phosphate $(\mathrm{mg} / \mathrm{g}), C_{0}$ and $C_{\mathrm{e}}$ are the initial and equilibrium concentrations $(\mathrm{mg} / \mathrm{L}), V$ is the solvent volume $(\mathrm{L})$, and $W$ is the weight of the adsorbent sample $(\mathrm{g})$. The date were expressed as the mean \pm standard error; $n=2$ or 3 .

Effect of the Solution pH on the Phosphate Ion Adsorption The adsorbent $(0.05 \mathrm{~g})$ was added to the phosphate ion solution $(10 \mathrm{mmol} / \mathrm{L}, 50 \mathrm{~mL})$ at different $\mathrm{pH}$ values $(\mathrm{pH}$ $2-13$ ). The $\mathrm{pH}$ of the solution was adjusted by adding 0.1 and $1.0 \mathrm{~mol} / \mathrm{L}$ hydrochloric acid or sodium hydroxide. The suspension was shaken at $100 \mathrm{rpm}$ for $24 \mathrm{~h}$ at $25^{\circ} \mathrm{C}$. The amount of adsorbed phosphate ions was calculated using Eq. (1).

Effect of the Temperature on the Phosphate Ion Adsorption The adsorbent $(0.05 \mathrm{~g})$ was added to the phosphate ion solution $(0.1,0.3,0.5,0.7,1,2,3,4$, or $5 \mathrm{mmol} / \mathrm{L}, 50 \mathrm{~mL})$. The sample solution was shaken at $100 \mathrm{rpm}$ at 5,25 , and $45^{\circ} \mathrm{C}$ for $24 \mathrm{~h}$ at $100 \mathrm{rpm}$. The amount of phosphate adsorbed was calculated using Eq. (1).

Effect of the Contact Time on the Adsorption The adsorbent $(0.05 \mathrm{~g})$ was added to the phosphate ion solution $(10 \mathrm{mmol} / \mathrm{L}, 50 \mathrm{~mL})$. The sample solution was shaken at $100 \mathrm{rpm}$ for $0.5,0.75,1,3,6,10,12,15$, and $20 \mathrm{~h}$ at at $25^{\circ} \mathrm{C}$. The amount of phosphate adsorbed was calculated using Eq. (1).

Phosphate Adsorption and Desorption Capability The adsorbent $(0.25 \mathrm{~g})$ was added to the phosphate ion solution $(100 \mathrm{mmol} / \mathrm{L}, 250 \mathrm{~mL})$. The sample solution was shaken at $100 \mathrm{rpm}$ for $24 \mathrm{~h}$ at $25^{\circ} \mathrm{C}$. The sample was then filtered, and the filtrate concentration was measured using the iCAP-7600 analyzer (ICP-OES, Thermo Fisher Scientific Inc., Japan). The amount of adsorbed phosphate was calculated using Eq. (1). Following adsorption, the adsorbent was collected, dried, and used for the desorption experiment. The collected adsorbent was added to a $250 \mathrm{~mL}$ solution of 10,100 , or $1000 \mathrm{mmol} / \mathrm{L}$ sodium hydroxide. The suspensions were shaken at $100 \mathrm{rpm}$ for $24 \mathrm{~h}$ at $25^{\circ} \mathrm{C}$ and filtered through a $0.45 \mu \mathrm{m}$ membrane filter. The amount of desorbed phosphate was calculated using Eq. (2) as shown below.

$$
d=\frac{C_{\mathrm{e}} V}{W}
$$

Where, $d$ is the amount of phosphate desorbed $(\mathrm{mg} / \mathrm{g}), C_{\mathrm{e}}$ is the concentration after desorption $(\mathrm{mg} / \mathrm{L}), V$ is the solvent volume (L), and $W$ is the weight of the adsorbent sample $(\mathrm{g})$.

The adsorption/desorption cycle of MFA1 using $10 \mathrm{mmol} / \mathrm{L}$ sodium hydroxide was repeated three times. The adsorbent $(0.25 \mathrm{~g})$ was added to the phosphate ion solution $(10 \mathrm{mmol} / \mathrm{L}$, $250 \mathrm{~mL}$ ). The amount of phosphate adsorbed was calculated using Eq. (2).

\section{Results and Discussion}

Properties of the Adsorbent SEM images of the adsorbents are shown in Fig. 1. We did not observe any difference in the MFA series, whereas the FHT3.0 and FHT5.0 exhibited a round morphology lacking a perfect crystal boundary, which has previously been reported in the literature. ${ }^{15)}$ The XRD patterns of the adsorbents are shown in Fig. 2. The patterns of the MFA series were completely different from those of the FHT series, which consisted of hydrotalcite-like layered double hydroxides. The basal reflections could be attributed to the (003) or (006) peaks, corresponding to the stacked brucitelike sheets. ${ }^{17)}$ However, while none of those peaks could be attributed to the MFA series, the intensity of the distinctive (A) peak was considered to be proportional to the molar ratio of aluminum in MFA: it was from the aluminum compound. Additionally, the surface $\mathrm{pH}$, specific surface area, and

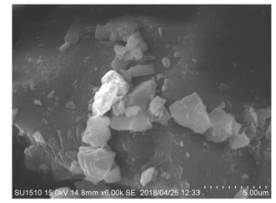

MFA1

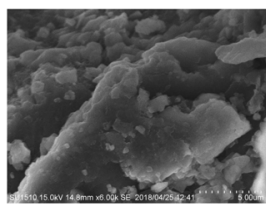

MA

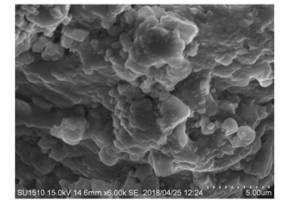

MFA2

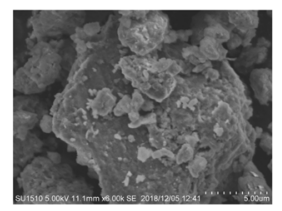

FHT3.0

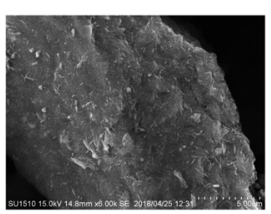

MF

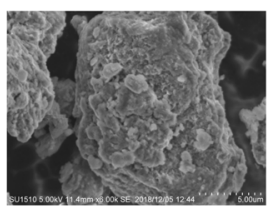

FHT5.0
Fig. 1. SEM Images of Adsorbents

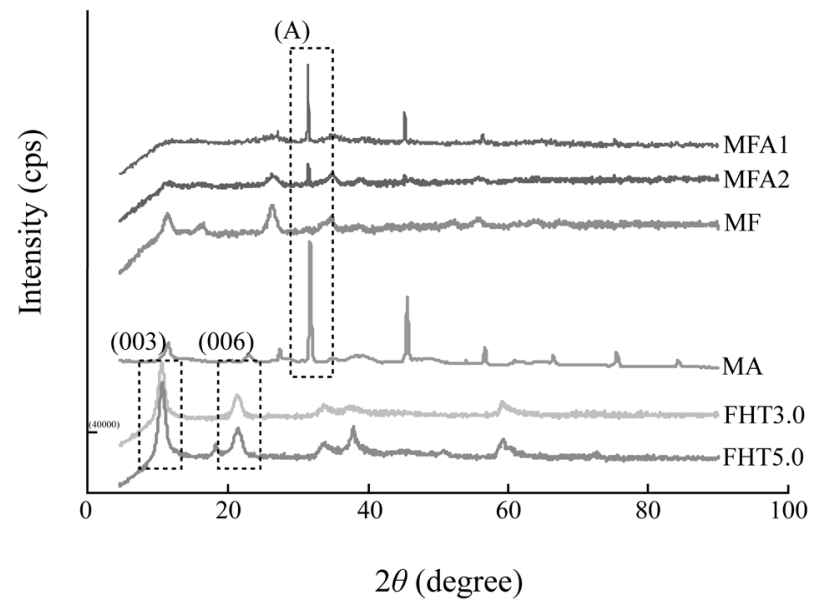

Fig. 2. XRD Pattern of Adsorbents

Table 1. Properties of Adsorbents

\begin{tabular}{cccc}
\hline \hline Samples & $\begin{array}{c}\text { Surface } \\
\mathrm{pH}\end{array}$ & $\begin{array}{c}\text { Specific suface area } \\
\left(\mathrm{m}^{2} / \mathrm{g}\right)\end{array}$ & $\begin{array}{c}\text { Amount of hydroxyl groups } \\
(\mathrm{mmol} / \mathrm{g})\end{array}$ \\
\hline MFA1 & 4.4 & 0.2 & 2.4 \\
MFA2 & 2.2 & 35.4 & 1 \\
MF & 2.5 & 87.9 & 0.3 \\
MA & 6.5 & 11.5 & 1.2 \\
FHT3.0 & 6.5 & 7.5 & 1.6 \\
FHT5.0 & 6.8 & 6.8 & 1.7 \\
\hline
\end{tabular}




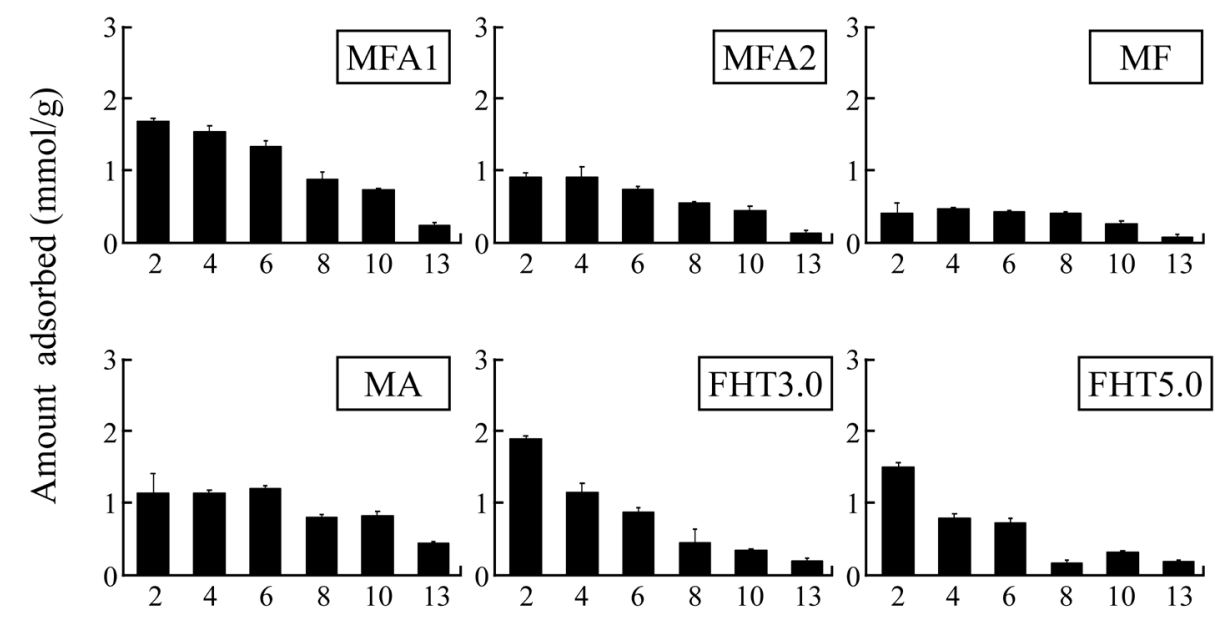

Initial $\mathrm{pH}$

Fig. 3. Effect of $\mathrm{pH}$ Solution on the Adsorption of Phosphate Ion

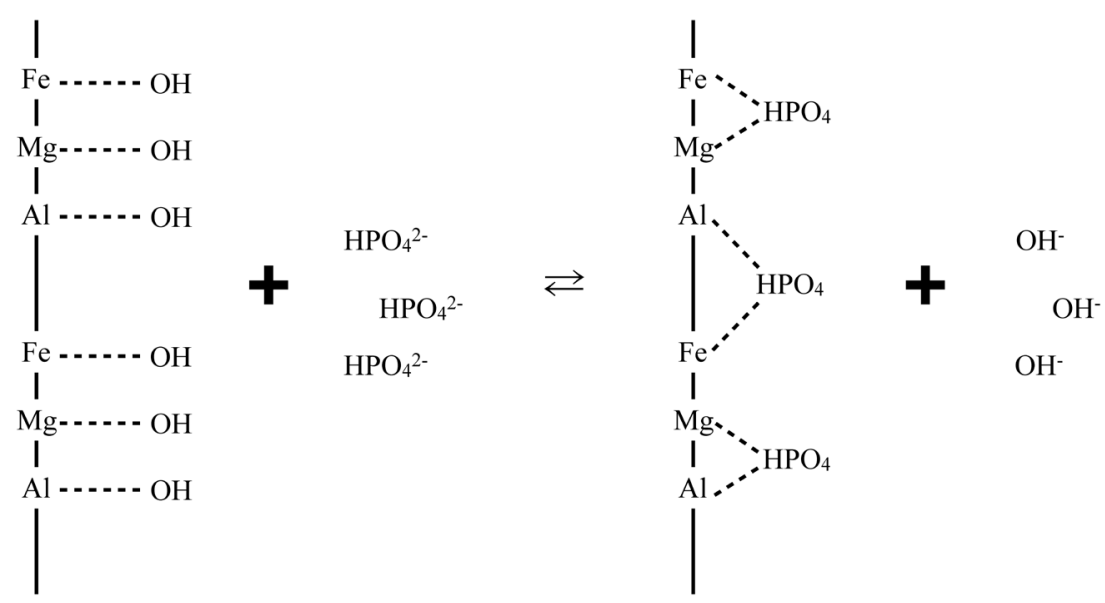

Fig. 4. Chart of the Adsorption Mechanism of Phosphate Ion from Aqueous Solution

amount of hydroxyl groups of the adsorbents are shown in Table 1. The MFA1, MFA3, or MF had an acidic surface $\mathrm{pH}$, while a neutral $\mathrm{pH}$ was seen otherwise. The specific surface area and amount of hydroxyl groups of MFA1, MFA2, MF, MA, FHT3.0, and FHT5.0 were 0.2, 35.4, 87.9, 11.5, 7.5, and $6.8 \mathrm{~m}^{2} / \mathrm{g}$, and $2.4,1.0,0.3,1.2,1.6$, and $1.7 \mathrm{mmol} / \mathrm{g}$, respectively. The MFA1 had a greater amount of hydroxyl groups as compared to the other adsorbents.

Amount of Phosphate Ions Adsorbed onto MFA and Effect of the pH Figure 3 shows the amount of phosphate ions adsorbed on the MFA series and FHT, and the results of the $\mathrm{pH}$ dependent adsorption experiments in solutions with an initial $\mathrm{pH}$ value in the $2-13$ range. The amount of phosphate ions that were adsorbed in the $\mathrm{pH}$ range 2.0-6.0 was greater than that at any other $\mathrm{pH}$, which indicated that the adsorption was $\mathrm{pH}$ dependent. Furthermore, the amount of phosphate ions adsorbed onto the MFA1 at a $\mathrm{pH}$ of 4.0 was greater than the adsorption on other adsorbents, which indicates that the MFA1 is conducive for the adsorption of phosphate ions from aqueous solutions. Phosphate exists as $\mathrm{H}_{2} \mathrm{PO}_{4}^{-}, \mathrm{HPO}_{4}^{2-}$, and $\mathrm{PO}_{4}^{3-}$ depending on the $\mathrm{pH}$ of the solution, with $\mathrm{p} K_{a 1}=2.15$, $\mathrm{p} K_{a 2}=7.2$, and $\mathrm{p} K_{a 3}=12.33$, respectively. Considering the $\mathrm{pH}$ range 2-6, $\mathrm{HPO}_{4}^{2-}$ is the dominant phosphate ion near

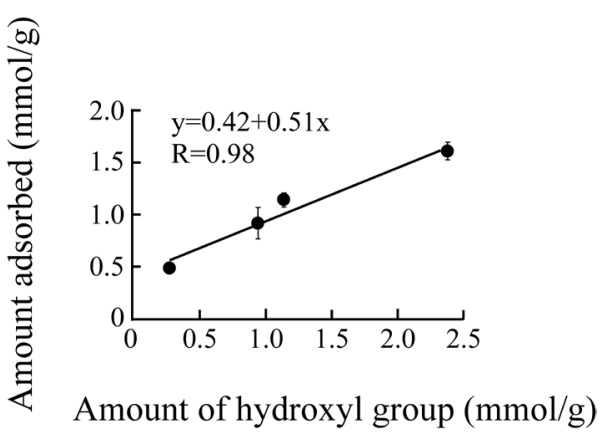

Fig. 5. Relationship between the Amount Adsorbed and the Amount of Hydroxyl Groups

a $\mathrm{pH} 4.0$ as the dominant phosphate species are $\mathrm{H}_{2} \mathrm{PO}_{4}^{-}$and $\mathrm{HPO}_{4}^{2-}$. Thus, ion exchange occurs between $\mathrm{HPO}_{4}^{2-}$ and the surface hydroxyl groups on the adsorbent (Fig. 4). Similarly, the adsorption behavior of the phosphate ions with respect to the other adsorbents has been reported in the literature. ${ }^{12)}$ Increasing the $\mathrm{pH}(>\mathrm{pH}$ 8.0) causes lesser ion exchange between $\mathrm{HPO}_{4}^{2-}$ and the surface hydroxyl groups in aqueous solution, as the ratio of $\mathrm{HPO}_{4}^{2-}$ decreases with an increase in the solution $\mathrm{pH}$. Furthermore, we investigated the relation- 
ship between the phosphate adsorption on the MFA series and amount of hydroxyl groups (Fig. 5). The correlation coefficient between the amount of adsorbed phosphate ions and hydroxyl groups is 0.98 , while the correlation between the amount of adsorbed phosphate ions and specific surface area is -0.95 (data not shown). The amount of phosphate ions adsorbed increased with an increase in the amount of hydroxyl groups and decrease in the specific surface area. The above results indicate that the phosphate ion adsorption with respect to the MFA series is related to the amount of adsorbent hydroxyl groups. The specific surface area has little contribution in the phosphate adsorption on the MFA, whereas the specific surface area and amount of adsorption are positively correlated in many adsorbents. ${ }^{11,12}$ Thus, the mechanism of phosphate ion adsorption on the MFA series differs from that seen in existing adsorbents, demonstrating that we were successful in developing a novel adsorbent for the phosphate ions from aqueous solutions.

Phosphate Ion Adsorption Isotherms of MFA1 To investigate the phosphate ion adsorption capacity of MFA, quantitative analysis and isotherms of the phosphate ion adsorption onto the MFA1 surface are presented in Figs. 6 and 7, respectively. The phosphate ions adsorbed onto MFA1 increased with increasing temperatures. The adsorption data were fitted using the Langmuir (Eq. (3)) and Freundlich (Eq. (4)) models

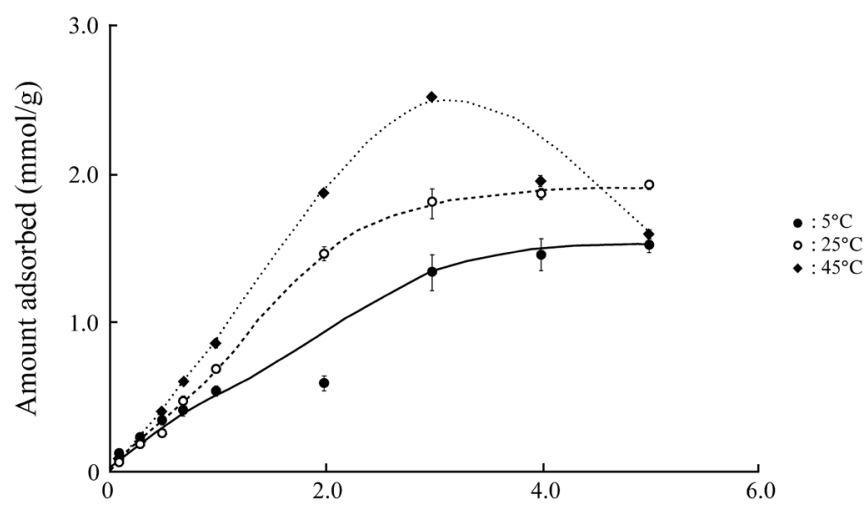

Equilibrium concentration ( $\mathrm{mmol} / \mathrm{L})$

Fig. 6. Adsorption Isotherm of Phosphate Ion onto MFA1 at Different Temperatures

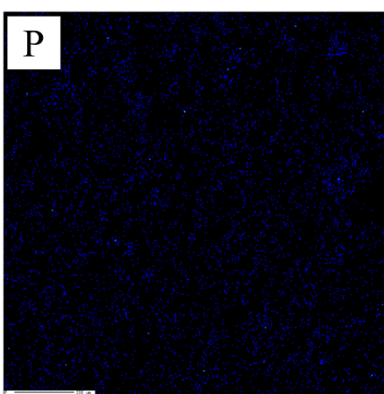

Before adsorption

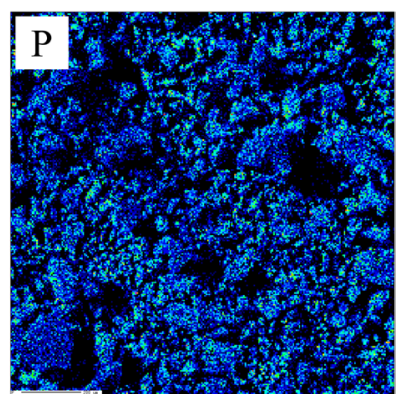

After adsorption
Low

High

Fig. 7. Quantitative Analysis of Phosphate Ion onto MFA1 Surface before and after Adsorption

(Color figure can be accessed in the online version.) as shown below.

$$
\begin{gathered}
\frac{C_{\mathrm{e}}}{q_{\mathrm{e}}}=\frac{1}{K_{\mathrm{L}} Q_{\mathrm{m}}}+\frac{C_{\mathrm{e}}}{Q_{\mathrm{m}}} \\
\log q_{\mathrm{e}}=\log K_{\mathrm{F}}+\frac{1}{n} \log C_{\mathrm{e}}
\end{gathered}
$$

Where, $C_{\mathrm{e}}(\mathrm{mg} / \mathrm{L})$ and $q_{\mathrm{e}}(\mathrm{mg} / \mathrm{g})$ are the equilibrium concentration of the adsorbate in the aqueous phase and equilibrium adsorption capacity, respectively, $Q_{\mathrm{m}}(\mathrm{mg} / \mathrm{g})$ is the maximum adsorption capacity, $K_{\mathrm{L}}(\mathrm{mg} / \mathrm{g})$ is the Langmuir adsorption equilibrium constant, $\mathrm{n}$ is the constant representing the Freundlich isotherm curvature, and $K_{\mathrm{F}}$ is the Freundlich constant. ${ }^{18)}$

The Freundlich and Langmuir constants for the adsorption of phosphate ions are listed in Table 2. The adsorption isotherm data at 25 and $45^{\circ} \mathrm{C}$ are in agreement with both the Langmuir $\left(R^{2}: 0.90-0.94\right)$ and Freundlich $\left(R^{2}: 0.85-0.94\right)$ isotherms. $\log K_{\mathrm{F}}$ (Freundlich constant) decreased with an increase in the temperature. The adsorbate is easily adsorbed when $1 / \mathrm{n}$ is in the range of $0.1-0.5$, while adsorption becomes difficult when $1 / n>2 .{ }^{19)}$ Our results $(1 / n: 1.55-1.61)$ indicate that the phosphate ion was adsorbed onto MFA1. Additionally, the $Q_{\mathrm{m}}(7.96-9.19 \mathrm{mg} / \mathrm{g})$ values tend to decrease with an increase in the temperature, which is in agreement with the adsorption isotherm data.

The amount of phosphorus on the surface of MFA1 (Fig. 7, the cold and warm colors represent low and high concentrations, respectively) increased following phosphate ion adsorption. This result indicates that the adsorption of the phosphate ion onto MFA1 depends on the properties of the adsorbent surface, where ion exchange between $\mathrm{HPO}_{4}^{2-}$ and the surface hydroxyl groups occurs. Thus, we evaluated the binding energy before and after phosphorus adsorption (Fig. 8). The phosphorus peak (approximately $130 \mathrm{eV}$ ) was detected after

Table 2. Freundlich and Langmuir Constants for Adsorption of Phosphate Ions onto MFA1

\begin{tabular}{lrcccccc}
\hline \hline & \multicolumn{4}{c}{ Freundlich model } & \multicolumn{3}{c}{ Langmuir model } \\
\cline { 2 - 8 } Sample & & $1 / n$ & $\log K_{\mathrm{F}}$ & $R^{2}$ & $\begin{array}{c}K_{\mathrm{L}} \\
(\mathrm{L} / \mathrm{mg})\end{array}$ & $\begin{array}{c}Q_{\mathrm{m}} \\
(\mathrm{mg} / \mathrm{g})\end{array}$ & $R^{2}$ \\
\hline \multirow{2}{*}{ MFA1 } & $5^{\circ} \mathrm{C}$ & 0.40 & 0.61 & 0.71 & 2.72 & 6.64 & 0.01 \\
& $25^{\circ} \mathrm{C}$ & 1.55 & 0.31 & 0.94 & 0.07 & 9.19 & 0.94 \\
& $45^{\circ} \mathrm{C}$ & 1.61 & 0.21 & 0.90 & 0.16 & 7.96 & 0.85 \\
\hline
\end{tabular}

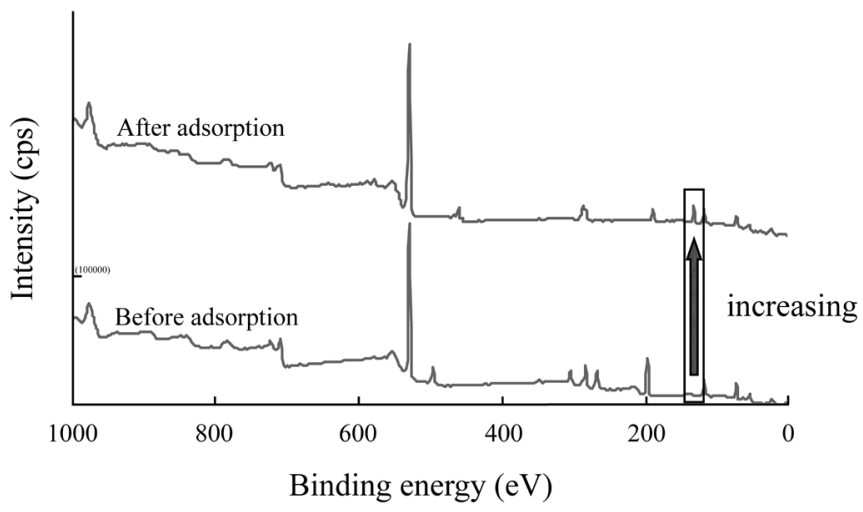

Fig. 8. Binding Energy before and after Adsorption of Phosphate Ion 
the adsorption of the phosphate ions. These results demonstrate that phosphorus could be adsorbed onto MFA1 from an aqueous solution.

Kinetics of the Adsorption of Phosphate Ions Kinetics of the adsorption of phosphate ions is shown in Fig. 9. Equilibrium adsorption was attained within 3 to $6 \mathrm{~h}$ for MFA1. The equilibrium adsorption capacity of the $\mathrm{Zn}-\mathrm{Al}$ layered double hydroxides can be attained within $72 \mathrm{~h}$, which has been reported previously. ${ }^{6}$ Thus, MFA1 is useful for the rapid removal of the phosphate ions in aqueous solution. The pseudo-first-order and pseudo-second-order kinetics models ${ }^{20)}$ expressed in Eqs. (5) and (6), respectively were used to fit the experimental adsorption data.

$$
\begin{gathered}
\ln \left(q_{\mathrm{e}}-q_{\mathrm{t}}\right)=\ln q_{\mathrm{e}}-k_{\mathrm{l}} t \\
\frac{t}{q_{\mathrm{t}}}=\frac{1}{\left(k_{2} q_{\mathrm{e}}^{2}\right)}+\frac{t}{q_{\mathrm{e}}}
\end{gathered}
$$

Where, $k_{1}$ and $k_{2}$ are the first-order and second-order apparent adsorption rate constants $(1 / \mathrm{h}$ and $\mathrm{g} / \mathrm{mg} / \mathrm{h})$, respectively, $q_{\mathrm{t}}$ and $q_{\mathrm{e}}$ are the amount of adsorbed phosphate ions $(\mathrm{mg} / \mathrm{g})$ at time $t$ and equilibrium, respectively. ${ }^{21)}$

Kinetics parameters of the pseudo-first-order and pseudosecond-order models are listed in Table 3. It was found that the phosphate ion adsorption can be better described using the pseudo-second-order kinetics model (0.86), as its correlation coefficient was higher than that of the pseudo-first-order kinetics model (0.47). Additionally, the value of $q_{\mathrm{e} \text { exp }}$ was nearer to the $q_{\mathrm{e}, \mathrm{cal}}$ of the pseudo-second-order kinetics model than that of the pseudo-first-order kinetics model. These results are consistent with the chemical behavior of phosphate ion adsorption exhibited by other hydrotalcite-like adsorbents. ${ }^{22}$

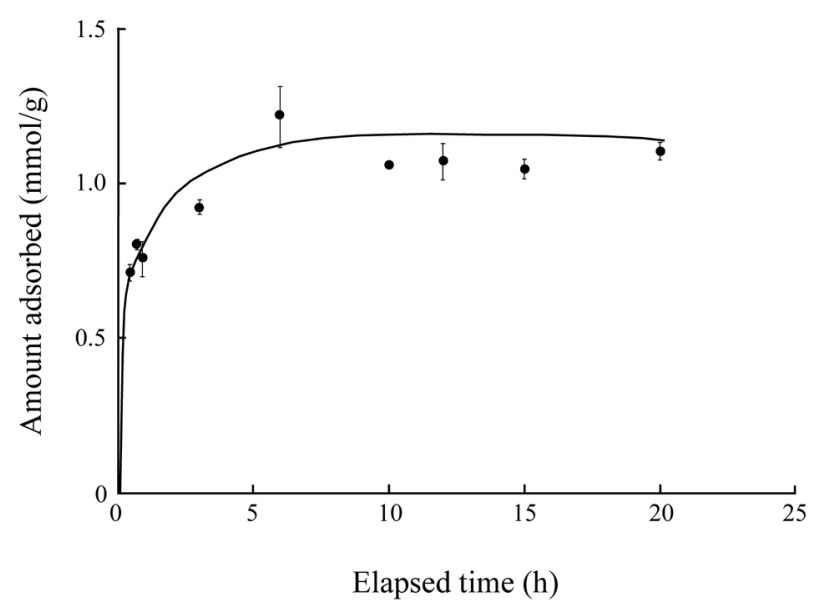

Fig. 9. Effect of Contact Time on the Adsorption of Phosphate Ion

Table 3. Kinetics Parameters for Pseudo-first-order and Pseudo-second-

\begin{tabular}{|c|c|c|c|c|c|c|c|}
\hline \multirow[b]{2}{*}{ Sample } & \multirow[b]{2}{*}{$\begin{array}{c}q_{\mathrm{e}, \mathrm{exp}} \\
(\mathrm{mg} / \mathrm{g})\end{array}$} & \multicolumn{3}{|c|}{ Pseudo-first-order model } & \multicolumn{3}{|c|}{ Pseudo-second-order mode } \\
\hline & & $\begin{array}{c}q_{\mathrm{e}, \mathrm{cal}} \\
(\mathrm{mg} / \mathrm{g})\end{array}$ & $\begin{array}{c}k_{1} \\
(1 / \mathrm{h})\end{array}$ & $R^{2}$ & $\begin{array}{c}q_{\mathrm{e}, \mathrm{cal}} \\
(\mathrm{mg} / \mathrm{g})\end{array}$ & $\begin{array}{c}k_{2} \\
(\mathrm{~g} / \mathrm{mg} / \mathrm{h})\end{array}$ & $R^{2}$ \\
\hline MFA1 & 57.9 & 31.9 & 0.02 & 0.47 & 44.4 & $2.15 \times 10^{-5}$ & 0.86 \\
\hline
\end{tabular}
order Models
Desorption of Phosphate Ions from MFA1 Using Sodium Hydroxide Recovery of the phosphate ions using sodium hydroxide at different concentrations is shown in Fig. 10. The desorption percentages for the phosphate ions at 10, 100, and $1000 \mathrm{mmol} / \mathrm{L}$ are $16.4,20.7$, and $12.4 \%$, respectively. In this study, the amount of desorbed phosphate ions did not change much with the concentration of sodium hydroxide. Thus, we believe that a $10 \mathrm{mmol} / \mathrm{L}$ sodium hydroxide concentration is sufficient to achieve phosphate desorption from MFA1. The repeated adsorption and desorption of the phosphate ions using a $10 \mathrm{mmol} / \mathrm{L}$ sodium hydroxide concentration is shown in Fig. 11. The experiment demonstrates that MFA1 can be recovered using sodium hydroxide solution, and the recovered MFA1 can be recycled. The total amounts of adsorbed and desorbed phosphate were 5.7 and $4.3 \mathrm{mmol} / \mathrm{g}$, respectively, with a recovery percentage of $75 \%$ using $10 \mathrm{mmol} / \mathrm{L}$ sodium hydroxide. In general, the adsorption capacity decreased in the adsorption/desorption cycles. However, in the case of MFA1 in our study, the amount of phosphate ions adsorbed on MFA1 did not decrease much, which indicates that MFA1 can be used repeatedly. Additionally, the amount of phosphate ion desorption increased with an increase in the number of cycles. These results indicate that MFA1 can be reused and recovered for phosphate ion adsorption using sodium hydroxide solution as an eluent, demonstrating its application/utility as a renewable adsorbent.

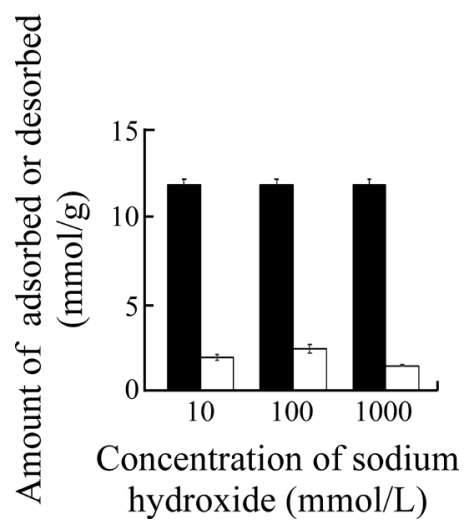

Fig. 10. Recovery of Phosphate Ion Using Sodium Hydroxide at Different Concentration

口: adsorption, $\square$ : desorption.

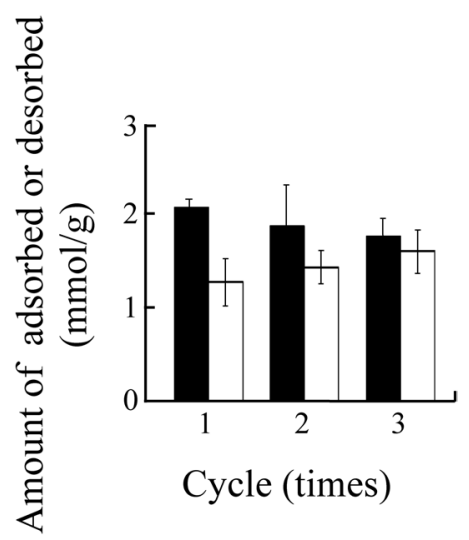

Fig. 11. Amount of Phosphate Ion Adsorbed or Desorbed Using MFA1 $\boldsymbol{\square}$ : adsorption, $\square$ : desorption. 
Table 4. Comparisons of Phosphate Ions Adsorption Capacity of Various Adsorbents

\begin{tabular}{|c|c|c|c|c|c|c|}
\hline Adsorbents & $\begin{array}{l}\text { Adsorption capacity } \\
(\mathrm{mg} / \mathrm{g})\end{array}$ & $\begin{array}{l}\text { Temperature } \\
\left({ }^{\circ} \mathrm{C}\right)\end{array}$ & $\begin{array}{l}\text { Initial concentration } \\
(\mathrm{mg} / \mathrm{L})\end{array}$ & $\begin{array}{c}\text { Contact time } \\
\text { (h) }\end{array}$ & $\begin{array}{l}\text { Adsorbent } \\
(\mathrm{g} / \mathrm{L})\end{array}$ & Reference \\
\hline HUD zeolite & 48.5 & Room temperature & 100 & 168 & 1 & 5) \\
\hline Fe-Bentnite & 4.84 & Room temperature & 20 & 6 & 4 & 6) \\
\hline Zn-Al double hydroxide & 25.0 & Room temperature & 16 & 24 & 0.4 & 7) \\
\hline Al hydroxide gel & 29.3 & Room temperature & 127 & 15 & 2 & 8) \\
\hline $\mathrm{Mg} / \mathrm{Fe}$ double hydroxide & 15.5 & Room temperature & 100 & 24 & 5 & 9) \\
\hline Fe-Doped activated carbon & 14.1 & Room temperature & 20 & 24 & 2 & 10) \\
\hline Calcined Ni hydroxide & 17.4 & Room temperature & 100 & 24 & 2 & 11) \\
\hline Fe-Mg hydrotalcite (FHT3.0) & 43.6 & Room temperature & 300 & 24 & 1 & This study \\
\hline $\mathrm{Fe}-\mathrm{Mg}$ hydrotalcite (FHT5.0) & 27.7 & Room temperature & 300 & 24 & 1 & This study \\
\hline MFA1 & 53.6 & Room temperature & 300 & 24 & 1 & This study \\
\hline
\end{tabular}

Comparison of Adsorption Capacities Comparisons between the phosphate ion adsorption capacities of the various adsorbents are listed in Table $4 .^{5-11)}$ The phosphate ion adsorption capacity of MFA1 is higher than that of the reported adsorbents, indicating that MFA1 can be repeatedly used for the adsorption of phosphate ions.

\section{Conclusion}

In summary, we prepared novel $\mathrm{Mg} / \mathrm{Fe} / \mathrm{Al}$ hydroxides (MFA) at various ratios and evaluated the adsorption of phosphate ions from aqueous solutions. The degree of crystallinity in the MFA series was completely different from that of the FHT3.0 and FHT5.0. The amount of phosphate ions that were adsorbed onto the MFA series and FHT was $\mathrm{pH}$ dependent, with the amount of adsorption on MFA1 at a $\mathrm{pH}$ of 4.0 being greater than that seen in the other adsorbents $(1.6 \mathrm{mmol} / \mathrm{g}$ or $53.6 \mathrm{mg} / \mathrm{g}$ ). Additionally, the amount of surface hydroxyl groups of MFA1 was greater than that in the other adsorbents $(2.4 \mathrm{mmol} / \mathrm{g})$. The strong correlation (coefficient of 0.98$)$ between the amount of adsorbed phosphate ions and surface hydroxyl groups indicates the occurrence of ion exchange on the MFA1 between $\mathrm{HPO}_{4}^{2-}$ and the surface hydroxyl groups. The adsorption isotherm data were fitted using both the Freundlich and Langmuir models, with the adsorption kinetics following the pseudo-second-order model. Additionally, the adsorbed phosphate ions on MFA1 were desorbed using sodium hydroxyl solution with a total recovery percentage of $75 \%$. We also observed that the phosphate ion adsorption capacity of MFA1 was higher than that reported for the other adsorbents. In conclusion, the results from this study demonstrate that the novel MFA adsorbent offers great potential for phosphate ion adsorption from aqueous solutions.

Acknowledgments The Research Foundation for Pharmaceutical Sciences.

Conflict of Interest The authors declare no conflict of interest.

\section{References}

1) Barca C., Gérente C., Meyer D., Chazarenc F., Andrés Y., Water Res., 46, 2376-2384 (2012).

2) Vohla C., Kõiv M., Bavor H. J., Chazarenc F., Mander Ü., Ecol. Eng., 37, 70-89 (2011).

3) Gao J., Xiong Z., Zhang J., Zhang F., Desalination, 242, 193 (2009).

4) Jin X., Wang S., Pang Y., Zhao H., Zhou X., Colloids Surf. A Physicochem. Eng. Asp., 254, 241-248 (2005)

5) Onyango M. S., Kuchar D., Kubota M., Matsuda H., Ind. Eng. Chem. Res., 46, 894-900 (2007).

6) Yan L., Xu Y., Yu H., Xin X., Wei Q., Du B., J. Hazard. Mater. 179, 244-250 (2010).

7) Cheng X., Huang X., Wang X., Zhao B., Chen A., Sun D., J. Hazard. Mater., 169, 958-964 (2009).

8) Kawasaki N., Ogata F., Tominaga H., J. Hazard. Mater., 181, 574 579 (2010).

9) Seida Y., Nakano Y., Water Res., 36, 1306-1312 (2002).

10) Wang Z., Nie E., Li J., Yang M., Zhao Y., Luo X., Zheng Z., Environ. Sci. Pollut. Res. Int., 19, 2908-2917 (2012).

11) Ogata F., Imai D., Toda M., Otani M., Kawasaki N., J. Ind. Eng. Chem., 34, 172-179 (2016).

12) Ogata F., Imai D., Toda M., Otani M., Kawasaki N., J. Environ. Chem. Eng., 3, 1570-1577 (2015).

13) Yamashita T., Ozawa Y., Nakajima N., Murata T., Nippon Kagaku Kaishi, 8, 1057-1061 (1978).

14) Wimonsong P., Llorca J., Nitisoravut R., Int. J. Hydrogen Energy, 38, 349 (2009).

15) Ogata F., Nakamura T., Ueta E., Nagahashi E., Kobayashi Y., Kawasakii N., Envirn J., Chem. Eng., 5, 3083 (2017).

16) Ogata F., Kawasaki N., Chem. Pharm. Bull., 63, 1040-1046 (2010).

17) Türk T., Alp İ., J. Ind. Eng. Chem., 20, 732-738 (2014).

18) Köse T. E., Kivanc B., Chem. Eng. J., 178, 34-39 (2011).

19) Abe I., Hayashi K., Kitagawa M., Oil Chem. J. J. Soc., 25, 145 (1976).

20) Li R. H., Yue Q. L., Shen F., Qin R., Zhang G. J., Li Z. H., Zhang Z. Q. Fresen., Fresen. Fresen. Environ. Bull., 22, 177 (2013).

21) Li R., Wang J. J., Zhou B., Awasthi M. K., Ali A., Zhang Z., Gaston L. A., Lahori A. H., Mahar A., Sci. Total Environ., 559, 121-129 (2016).

22) Yang K., Yan L., Yang Y., Yu S., Shan R., Yu H., Zhu B., Du B., Separ. Purif. Tech., 124, 36-42 (2014). 